La violencia homofóbica en la escuela peruana y sus particularidades respecto a otros tipos de violencia escolar: Una exploración cuantitativa ${ }^{1}$

Homophobic violence in the peruvian school and its peculiarities with respect to other types of school violence: a quantitative exploration

\author{
Lucero Cuba Varas \\ Pontificia Universidad Católica del Perú \\ lucero.cuba@pucp.pe \\ Tomás Osores Gonzáles ${ }^{2}$ \\ Ministerio de Desarrollo e Inclusión Social \\ tomasosores@gmail.com
}

Recibido: 16-04-2017

Aprobado: 02-10-2017

1. Este artículo se desprende de la investigación Violencia escolar por homofobia y racismo, ¿de qué depende?, realizada por Lucero Cuba y Tomás Osores, y ganadora del concurso nacional «Investigando la Violencia Escolar en el Perú».

2. Osores brindó el apoyo en minería de datos. 


\title{
Resumen
}

El presente artículo analiza las características de la denominada «violencia homofóbica» en la escuela (aquella ejercida hacia los y las estudiantes que declaran que son agredidos por ser reconocidos bajo las categorías de «maricón», «gay», «lesbiana» 0 «machona»). Así mismo, identifica sus particularidades y diferencias frente a otros tipos de violencia escolar (como aquellas se reconoce que están causadas por el origen étnico, la discapacidad física, el estatus socioeconómico, entre otras). Sobre la base de la Encuesta de Convivencia Escolar de la prueba piloto de la Evaluación Censal de Estudiantes 2013, aplicada a 47.114 estudiantes de quinto de secundaria, se construyeron subpoblaciones de afectados por violencia homofóbica, así como por violencia en general. A partir de un análisis descriptivo y comparativo, se encontró una relación entre el hecho de ser afectado por violencia escolar homofóbica, y el ser hombre y de escuela urbana. Además, se halló que, en comparación con los afectados por otras violencias, el subgrupo afectado por violencia homofóbica se encontraría en una situación más vulnerable, tanto por la mayor frecuencia del hostigamiento como por sus percepciones del clima escolar, el bienestar subjetivo, el bajo rendimiento, el consumo de sustancias y su exposición a la violencia en otros entornos. Mediante una primera exploración cuantitativa para escuelas de todo el país, se destaca, finalmente, la posibilidad de sugerir nuevas preguntas tanto sobre la violencia homofóbica como sobre distintos aspectos de la convivencia escolar.

Palabras clave: Violencia, escuela, homofobia, acoso escolar

\begin{abstract}
This article analyzes the characteristics of the "homophobic violence» at schools (the one applied to students who declare they are assaulted for being recognized as "gay" or «lesbian») and, in the same way, it identifies itsparticularities and differences from other types of school violence (like those recognized to be caused by ethnic origin, physical disability or socioeconomic status). Based on the census-based National Student Assessment 2013 (questionnaire on school interactions), applied to final high school grade (5th) students, two sub populations were identified: those affected by both homophobic violence and violence in general. Following a descriptive analysis, binomial logistic regression models were constructed for both sub populations. A direct correlation was found between being affected by homophobic school violence and the fact of being a man and attending an urban school. Likewise, it was showed that, in comparison with those affected by other kinds of violence, the homophobic violence victims are in a more vulnerable situation, both by the higher prevalence of harassment as well as their perceptions of the school climate, subjective well-being, and, finally, as reporting poor performance, substance use, and exposure to violence in other settings. Being a first quantitative exploration for Peruvian schools, the possibility of suggesting new questions about homophobic violence, as well as the
\end{abstract} 140 I pieces of school life, stand out.

Keywords: Violence, school, homophobia, harassment 


\section{La violencia homofóbica en la escuela peruana y sus particularidades respecto a otros tipos de violencia escolar: Una exploración cuantitativa}

\section{Introducción}

Desde una perspectiva sociológica, la escuela es un espacio fundamental en la reproducción de la sociedad (tanto sus valores y prejuicios, como sus jerarquías a escalas local y societal) y, por ende, también en sus procesos de transformación. Así, en tanto espacio de disputa, es objeto de diferentes intereses políticos. Si bien se reconocen carencias en las políticas y recursos al sector por buena parte de los gobiernos, lo cierto es que la educación siempre ha sido objeto de interés público: las políticas de acceso universal a la educación gratuita, magisteriales, contra la violencia escolar, entre otras, cada una en su tiempo, han sido objeto del debate y de la opinión en la esfera pública. Por eso, hablar de violencia escolar no es hablar de un fenómeno neutro o terminado, sino de un espacio en permanente pugna a nivel de interpretaciones y de estrategias. En ese marco, para algunos sectores de la sociedad, la violencia escolar por homofobia no constituye realmente un problema, mientras que, para otros, desde donde nos situamos, se trata de un problema invisibilizado y que requiere de atención urgente ${ }^{3}$.

La presente investigación se aproxima al fenómeno de la violencia escolar asociada a la homofobia ${ }^{4}$. De reciente visualización, a pesar de su existencia cotidiana, la violencia escolar motivada por actitudes homofóbicas requiere no solo de políticas públicas para combatirla, sino de mayor investigación sobre sus dinámicas específicas. Si bien la violencia escolar en general es un problema grave que perjudica el bienestar y el aprendizaje de las y los estudiantes, la violencia escolar por homofobia tiene dinámicas propias que ameritarían ser atendidas en su especificidad (Ortiz-Hernández \& García, 2005; Pichardo,

3. Desde fines de 2016, hemos sido testigos de cómo el Currículo Nacional 2016 se ha vuelto objeto de interés público, principalmente, por los aspectos relacionados con el enfoque de igualdad de género y las orientaciones generales sobre sexualidad (como la no discriminación por orientación sexual y algunas pautas de educación sexual) que en este se mencionan. Un grupo de interés es el conformado por políticos, iglesias cristianas y organizaciones religiosas, desde argumentos religiosos, busca eliminar el enfoque de género y que en las escuelas no se haga mención alguna sobre las diversas formas que la sexualidad puede adquirir. Por otro lado, estamos quienes apostamos por hacer de la escuela un espacio más seguro para las niñas y niños, desde sus diversidades, así como una posibilidad de transformación de paradigmas culturales que generan violencia y discriminación como son el machismo, la homofobia, el racismo, entre otros, el cual se diputa en las aulas a través de instrumentos como el currículo.

4. Conceptos centrales como este serán desarrollados en la subsiguiente sección. 
2006). Ejemplo de ello es el profundo daño que puede generar en sus víctimas ${ }^{5}$. Es decir, combatir la violencia escolar por homofobia requiere, entre sus múltiples acciones, combatir las ideas que subyacen a la homofobia, y, por ello, promover el respeto a las diversidades sexuales y de género.

Estudios y reportes sobre la violencia escolar en el Perú dan cuenta de una alta incidencia de violencia entre escolares en distintas regiones del Perú (Oliveros \& Barrientos 2007; Oliveros et al. 2008; Amemiya et al. 2009; Ministerio de Educación 2017). Además de ello, es común que las agresiones no sean comunicadas a adultos en la escuela o, cuando lo son, estos no reaccionan, impunidad que legitima y reproduce la dinámica de violencia. En esa línea, un estudio en una ciudad de la Amazonía peruana da cuenta de la relación entre violencia escolar e ideación suicida (Cano, Gutiérrez \& Nizama, 2009).

La violencia por homofobia en la escuela, por su parte, no ha sido tan explorada en el Perú. Como aproximaciones interesantes, un estudio de Cáceres y Salazar (2013) da cuenta de cómo el bullying, si bien tiene alta incidencia entre escolares en general, es mucho mayor entre los no heterosexuales. El estudio plantea que el ambiente escolar normaliza y favorece el bullying homofóbico. Por otra parte, el estudio de Rondán (2015) en una escuela de Lima evidencia la asociación entre la masculinidad hegemónica, el rechazo al ser gay y la constante feminización simbólica entre varones como forma de reafirmar la propia masculinidad. Finalmente, Del Castillo (2001) muestra que, en la escuela, los niños aprenden desde muy temprano el ejercicio de la exclusión mediante la categoría "maricón», término asociado al erotismo prohibido entre varones, y que el «afeminado» de la clase suele ser el elegido como objeto del estigma «maricón». Estos tres estudios se aproximan a la homofobia entre o hacia adolescentes varones.

Frente a esta revisión, el presente artículo busca contribuir con el estudio de la violencia homofóbica en las escuelas a partir del análisis de aquellos aspectos de esta que la hacen particular respecto de otros tipos de violencia escolar, así como plantear interpretaciones a los resultados obtenidos, plantear hipótesis y generar nuevas preguntas.

\section{Objetivos de investigación}

A modo de hipótesis de trabajo, consideramos que no todos los tipos de violencia escolar operan del mismo modo, y, en ese sentido, que la violencia escolar por homofobia se distingue de otros tipos de violencia escolar al ser más intensa y agresiva con sus víctimas. Todas las dimensiones analizadas de la violencia escolar homofóbica están atravesadas por este análisis comparativo. Frente a

5. Según la Red Peruana TLGB y Promsex (2015), entre abril de 2014 y marzo de 2015, se registraron 4 casos de suicidios de personas LGTB. Todas tenían en común experiencias cotidianas de homofobia en sus entornos familiar y escolar. Tres de esos casos eran adolescentes de entre 12 y 18 años. 
ello y en el marco de las posibilidades de explotación de datos que nos permitió la ECE 2013, se plantearon 3 objetivos para la presente investigación. En primer lugar, se busca describir y analizar las características sociodemográficas significativas de las y los estudiantes afectadas/os por violencia homofóbica en la escuela. En segundo lugar, se apunta a describir y a analizar las manifestaciones de la violencia por homofobia que se distinguen de otras formas de violencia escolar, y el impacto que esta podría tener en la percepción sobre el clima escolar y en el bienestar subjetivo. Finalmente, se procura explorar la relación entre la violencia homofóbica y los problemas asociados a la violencia escolar, como son la violencia en otras relaciones sociales, el consumo de alcohol y drogas, y el ausentismo y el bajo rendimiento.

\section{Metodología}

La principal fuente de trabajo fue la base de datos de la Encuesta de Convivencia Escolar, que fue un bloque anexo de la prueba piloto de una Evaluación Censal de Estudiantes, aplicada por el Ministerio de Educación (Minedu, 2013) a estudiantes de quinto de secundaria en noviembre de $2013^{6}$. La Encuesta de Convivencia Escolar fue aplicada a 47.114 estudiantes a nivel nacional siguiendo un muestreo aleatorio simple ${ }^{7}$. La tabla 1 muestra la heterogeneidad de la población encuestada.

6. Hasta donde se tiene conocimiento, esta es la única y última encuesta de este tipo aplicada en secundaria.

7. Según la fuente consultada de la Unidad de Medición de la Calidad Educativa del Ministerio de Educación (2017), la aplicación de la prueba piloto de la Evaluación Censal de Estudiantes tuvo como propósito evaluar las pruebas y el proceso de aplicación, por lo que la muestra se estableció mediante una selección aleatoria de escuelas (de la cual se excluyeron a aquellas con menos de diez estudiantes); sin embargo, no tuvo fijado un error de estimación, pues no era el propósito realizar inferencias. Además, si bien la Evaluación Censal de Estudiantes definió su muestra en 65.000 estudiantes, esta (y la Encuesta de Convivencia Escolar adjunta) se aplicó finalmente a 47.114 estudiantes. Este desfase se debió a cuestiones logísticas esperables en una aplicación de carácter piloto. Finalmente, podemos decir que, si bien es una muestra a nivel nacional, no constituye una muestra probabilística que permita extraer conclusiones generalizables más allá de la muestra. 
Tabla 1. Estructura poblacional de los estudiantes de la muestra ECE 2013

\begin{tabular}{|c|c|c|}
\hline & $\mathrm{N}^{\circ}$ de estudiantes & $\%$ de estudiantes \\
\hline Total encuestados & 47.114 & 100 \\
\hline \multicolumn{3}{|c|}{ Sexo } \\
\hline Hombre & 23.550 & 49,9 \\
\hline Mujer & 22.754 & 48,3 \\
\hline \multicolumn{3}{|c|}{ Tipo de gestión de la escuela } \\
\hline Pública & 34.924 & 74,1 \\
\hline Privada & 12.181 & 25,9 \\
\hline \multicolumn{3}{|c|}{ Ámbito } \\
\hline Rural & 3076 & 6,5 \\
\hline Urbano & 44.038 & 93,5 \\
\hline \multicolumn{3}{|l|}{ Edad } \\
\hline 16 y 17 años & 39.981 & 84,8 \\
\hline Otros & 6026 & 12,8 \\
\hline \multicolumn{3}{|c|}{ Departamento } \\
\hline Lima & 15.498 & 32.9 \\
\hline Lambayeque & 3661 & 7,8 \\
\hline Junín & 3519 & 7,5 \\
\hline Piura & 2917 & 6,2 \\
\hline Puno & 2875 & 6,1 \\
\hline Ica & 2414 & 5,1 \\
\hline La Libertad & 1992 & 4.2 \\
\hline Arequipa & 1739 & 3.7 \\
\hline Cusco & 1706 & 3.6 \\
\hline Cajamarca & 1506 & 3.2 \\
\hline Otros (15) & 9287 & 19.7 \\
\hline
\end{tabular}

Fuente: Minedu (2013). Elaboración propia.

En Perú, el Estado no suele recoger información sobre la situación de personas lesbianas, gays, trans, bisexuales e intersexuales, o relacionada con la discriminación y la violencia homofóbicas. Desde la sociedad civil, ha habido esfuerzos por realizar estudios diagnósticos, entre los cuales, al margen de sus importantes aportes, pocos han sido estadísticamente representativos. Cuando el Ministerio de Educación convocó a su I Concurso Nacional «Investigando la Violencia Escolar en el Perú», en el que uno de los requisitos para participar era usar las bases de datos disponibles de encuestas nacionales, llamó nuestra 
atención que, en una de ellas, había una pregunta que permitía aproximarse a la violencia homofóbica en las escuelas por primera vez a escala nacional y a partir de datos oficiales. El carácter sui generis de este tipo de información fue una de las principales motivaciones para plantear la investigación realizada.

\subsection{Construcción de la población afectada por violencia homofóbica}

El primer paso en el tratamiento de la información fue el establecimiento de grupos de afectados por violencia en general (VG) y afectados por violencia homofóbica $(\mathrm{VH})$. Para empezar el análisis en torno a la constitución de una población de víctimas de violencia escolar, cabe resaltar la brecha entre los estudiantes que reconocen haber recibido algún tipo de agresión (el 79\% o 37.218 estudiantes) y aquellos que se reconocen como víctimas de agresión por algún motivo dado (solo el $31 \%$ o 14.520 estudiantes). Es probable que esta brecha se deba a la diferencia que existe entre reconocer que alguna vez alguien ha sido agredido frente a reconocer que eres objeto de violencia en la escuela, lo cual a algunos podría darles una noción de una condición permanente con la que no se identifican o no desean reconocer. Por ende, si bien ocho de cada diez ha sido objeto de algún tipo de agresión, solo tres se identifican a sí mismos como objeto de agresiones por algún motivo (incluido «otros»). Así, se decidió definir a las subpoblaciones a partir de los 14.520 (31\%) de estudiantes que se reconocen víctimas de violencia por algún motivo, a los cuales denominamos «afectados por violencia en general».

De ellos, 684 son afectados por violencia homofóbica específicamente, aquellos quienes ante la pregunta «¿Por qué crees que te pasó [el episodio de violencia]?» marcaron la opción «Porque me dicen maricón, gay, lesbiana, machona». Esta es la única variable del cuestionario que da cuenta de este tipo de violencia (medida por incidencias de agresión) a partir de la manifestación específica de homofobia que consiste en insultar al otro/a usando este tipo de categorías consideradas peyorativas. Consideramos que, si bien el número es reducido en relación con la muestra, podría reflejar una subrepresentación doble respecto del fenómeno de la violencia homofóbica por la dificultad personal de reconocerse como víctima y, por otra parte, la dificultad metodológica de solo incluir la indagación de una causa para los insultos, pese a que la homofobia se manifiesta de múltiples maneras. A pesar de los límites en términos de significatividad de la muestra y del reducido tamaño de esta subpoblación, consideramos que es una oportunidad sin precedentes para explorar las características de la violencia homofóbica y su relación con otros fenómenos. 
Gráfico 1. Definición de subpoblaciones

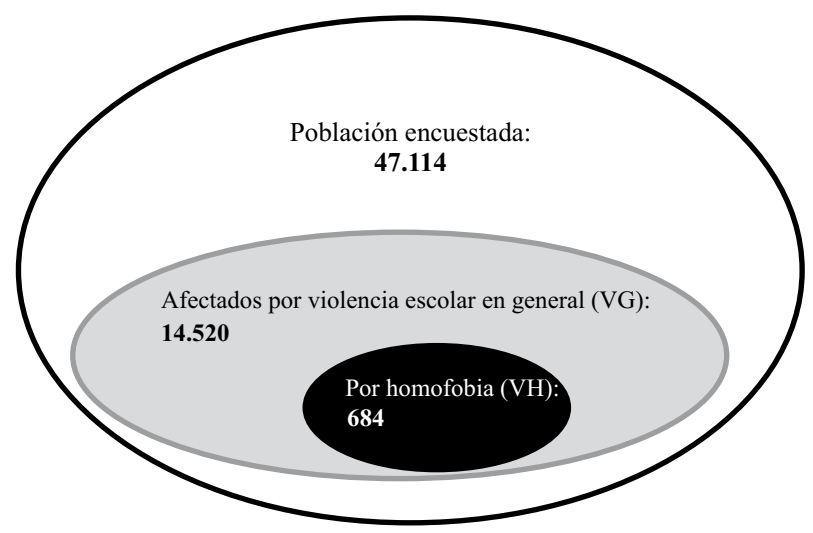

Fuente: Elaboración propia

Luego, se realizó un análisis descriptivo general de las variables del cuestionario (manifestaciones, respuestas y consecuencias de la violencia) para caracterizar a las poblaciones de afectados por violencia en general y los afectados por violencia homofóbica. A lo largo del análisis, se muestra o descarta el efecto especificador de la violencia homofóbica en relación con los afectados por violencia en general para algunas variables ${ }^{8}$.

\section{Homofobia en la escuela: Conceptos generales}

Conviene aclarar dos conceptos operativos que aparecen a lo largo del artículo: violencia escolar y homofobia. Para hacer referencia a la violencia en las escuelas, usualmente se utiliza el vocablo «bullying», como si se tratara de términos intercambiables; sin embargo, esto no es preciso. Mientras que el bullying hace alusión al acoso y violencia entre pares, que podría circunscribirse a las relaciones entre escolares, pero, también, a otro tipo de relaciones (compañeros de barrio, etc.), la violencia escolar implica diversos tipos de violencias que involucran a varios actores presentes en la escuela (estudiantes, docentes, directivos, auxiliares, etc.) (García \& Ascensio, 2015). Es importante hacer esta distinción, debido a que, al hablar de violencia escolar, se entiende que las autoridades y los docentes pueden participar de las dinámicas de violencia en tanto agresores, cómplices o víctimas, y no solo como terceros o espectadores. Asimismo, en las dinámicas típicas a las que se hace referencia cuando se habla de bullying, aparecen la víctima, el agresor y los observadores casi como personajes fijos. En realidad, lo que se debe comprender al hablar de violencia escolar es que las

8. El desarrollo del análisis descriptivo figura en la siguiente sección. 
dinámicas de violencia no se ejercen solo en una dirección, sino que, más bien, se instalan como formas de interacción validadas socialmente. Es decir, al hablar de violencia escolar, es necesario entenderla como un problema social que emerge en contextos sociales específicos, y no únicamente como un problema de conducta, comportamiento o acción individuales (Flores-González et al., 2011, p. 334).

Con respecto a la homofobia, hay muchas formas de entenderla, pero en este artículo tomaremos la definición de Viñuales (2002), quien señala que es una actitud de rechazo hacia quienes ponen en cuestión, con sus discursos, sus prácticas o sus expresiones, los roles de género o las expectativas sociales asociadas a estos roles. Si bien hay quienes - no sin razón- han afirmado que no es el término más afortunado, en tanto no se trata en estricto de una fobia como trastorno psicológico, optamos por mantener su uso, puesto que se ha ganado cierta legitimidad en el discurso estatal, académico y mediático como problemática social que afecta a las personas LGTBI y de expresiones de género diversas.

Entendemos que la homofobia es, finalmente, una expresión de lo que Butler (2001) conceptualiza como prácticas de exclusión y abyección, propias de la matriz heterosexual, a determinadas expresiones sexuales y de género. La autora define a la matriz heterosexual como un

[...] modelo discursivo/epistémico de inteligibilidad de género, el cual supone que para que los cuerpos sean coherentes y tengan sentido debe haber un sexo estable expresado mediante un género estable (masculino expresa hombre, femenino expresa mujer) que se define históricamente y por oposición mediante la práctica obligatoria de la heterosexualidad (Butler, 2001, p. 38).

Así, el comprender el concepto de matriz heterosexual como modelo de inteligibilidad cultural es importante porque, según Butler (2001), el imperativo heterosexual permite ciertas identificaciones sexuales, mientras excluye y repudia otras. Estas identificaciones excluidas y repudiadas serían los seres abyectos.

En esa medida, la identificación sexual de acuerdo con la regulación del sexo no es un asunto menor, sino que es constitutivo de la formación del sujeto. Sostiene Butler que «la materialización de un sexo dado será esencial para la regulación de las prácticas identificatorias que procurarán persistentemente que el sujeto rechace la identificación con la abyección del sexo» (2002, p. 19). Entonces, la identificación sexual de los y las adolescentes no sería solo un aspecto de su subjetividad, sino que resulta un proceso central en la configuración de su posición, como sujeto o como abyecto, en la matriz heterosexual. En este orden, la abyección de ciertas identidades sexuales no es la excepción, sino parte de la norma en la configuración de identidades sexuales regidas por la matriz heterosexual; es decir, la matriz heterosexual (que implica feminidades 
y masculinidades determinadas, así como la obligatoriedad de la heterosexualidad) es, en sí misma, una forma de violencia simbólica que atraviesa las relaciones sociales y las instituciones en general. Se trata de violencia simbólica entendida desde la perspectiva de Bourdieu (1999), que refiere a aquella que establece sumisiones que ni siquiera se perciben como tales en tanto están instaladas en creencias socialmente inculcadas: la sociedad en general presume y espera que, si alguien rompe con la heteronorma, reciba alguna forma de sanción o segregación en la medida que no es «normal».

Autores que han estudiado las relaciones existentes entre el ámbito escolar y la sexualidad, como Morgade (2011), han planteado que, en efecto, las escuelas funcionan como espacios de reproducción de la matriz heterosexual. Asimismo, junto con Morgade, Espinosa (2004), Rosales (2008) y Rondán (2015) coinciden en que, en la escuela -ya sea mediante la educación formal, o mediante las prácticas sociales en los espacios formales e informales-, se ponen en juego formas de comprender y encarnar la feminidad y la masculinidad específicas, que son reforzadas si se consideran aceptables o rechazadas si se consideran inaceptables. Entre las rechazadas, están la homosexualidad; la transgeneridad; $y$, en general, las expresiones de varones que no se ajusten a lo definido como masculino o de mujeres que no se ajusten a lo femenino. De hecho, la sexualidad misma es tratada desde un lenguaje cargado de sentidos pecaminosos y sesgados por el sistema de sexo-género (Morgade, 2011, p. 79).

$\mathrm{Al}$ analizar la violencia homofóbica en la escuela, es necesario abordarla considerando sus especificidades. Según Pichardo (2006), son las siguientes: la invisibilización, la ausencia de apoyo familiar, el contagio del estigma, el horizonte de la injuria, el continuo de la homofobia y la normalización de la homofobia. Este autor señala que la invisibilización contribuye a reproducir la violencia en la escuela. Sin embargo, los estudiantes perciben la homofobia no solo en la escuela, sino también en sus entornos familiares, por lo que, si son violentados en la escuela, no recurrirían a su familia o, en caso lo hicieran, probablemente, no recibirían el mismo respaldo que si se tratara de otros tipos de violencia.

El contagio del estigma es otra de sus especificidades, pues es probable que quien apoye o defienda a la víctima de violencia homofóbica sea también estigmatizado bajo la misma homofobia por sus compañeros. Por horizonte de la injuria, Pichardo (2006) se refiere a que toda expresión de violencia homofóbica afecta no solo a la persona específica que es agredida, sino a los estudiantes con orientaciones sexuales o identidades de género diversas, quienes interpretan dicha violencia como una advertencia o eventual castigo. Por su parte, el continuo de la homofobia hace referencia a que esta se halla no solo en la escuela, sino también en el hogar, los espacios públicos, los medios de comunicación, las iglesias, etc. Finalmente, la normalización de la homofobia se relaciona con cómo los distintos actores sociales en la escuela consideran que las bromas o actitudes homofóbicas son parte de una dinámica tolerable o normal. 


\section{Resultados y análisis}

Se ha organizado los resultados obtenidos en seis acápites. El primero y el segundo dan cuenta de las principales características sociodemográficas de los estudiantes afectados por violencia homofóbica en la escuela. En el tercero, se analizan las manifestaciones de la violencia escolar homofóbica. En el cuarto y el quinto, se analiza la relación entre la violencia homofóbica, el clima escolar y el bienestar subjetivo. El último acápite explora algunos problemas asociados a la violencia escolar, como son la violencia en otras relaciones sociales (hogar, pareja), el consumo de alcohol y drogas, y el ausentismo y el bajo rendimiento.

\subsection{Un fenómeno principalmente masculino}

Los resultados muestran que, si bien los afectados por violencia en general son varones en su mayoría (57\%), esta diferencia se acentúa considerablemente cuando se trata de violencia homofóbica, marco en que casi 4 de cada 5 afectados son varones (ver gráfico 2). En ese sentido, se trata de un fenómeno principalmente masculino.

Gráfico 2. Afectados por violencia homofóbica (VH)

y violencia en general (VG) según sexo

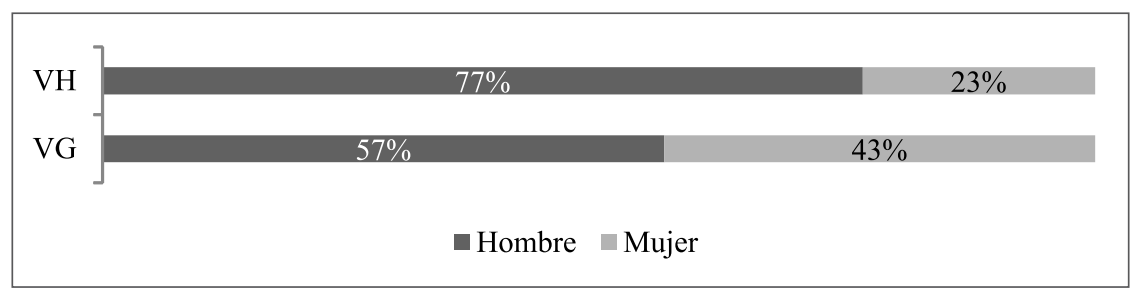

Fuente: Minedu (2013). Elaboración propia.

El análisis muestra que el identificarse como hombre es la variable que más se correlaciona con la violencia homofóbica en la escuela. Esto va en la línea de estudios que encuentran asociación entre violencia escolar por homofobia e identidades masculinas (Mollericona et al., 2011; Penna 2015). Para plantear una interpretación de estos resultados, tomamos la propuesta de Vásquez (2013) sobre el capital masculino en el marco de los estudios sobre masculinidades. Al respecto, Vásquez sostiene que la masculinidad no es algo dado o natural de los varones, sino que es un estatus que un varón debe demostrar y debe ganarse, ejercicio que se realiza permanentemente. No obstante, hay un momento en que esta demostración parece ser crucial: la adolescencia. En dicho tránsito hacia la juventud y la adultez, los varones deben dejar de ser niños y demostrar que merecen ser considerados hombres. 
Según Vásquez (2013), ese «volverse hombres» es el conjunto de cinco principales procesos para obtener el capital masculino: (i) el rechazo del mundo femenino y la conducta femenina, (ii) el rechazo de la homosexualidad, (iii) el debut heterosexual y el alarde del desempeño sexual, (iv) el riesgo y la violencia, y (v) la incorporación de valores morales masculinos. Sobre el rechazo de lo homosexual, este se complejiza en tanto los adolescentes deben aprender a lidiar con el homoerotismo presente en las relaciones entre varones y la constante homofobia. En un contexto masculino, la feminización de un hombre por otro hombre es un acto constante con el que los adolescentes deben aprender a lidiar sin alegrarse (puesto que no debe gustarles) ni tampoco ofenderse (en la medida que eso revelaría inseguridad). Más bien, deben feminizar a otro hombre; de ese modo, «se deshacen» de la feminización inicial de sí mismos. Esto es importante, porque da una descripción sobre cómo es que funciona la homofobia entre varones en la cotidianeidad. En esa medida, no hace falta que haya algún adolescente abiertamente homosexual para que se ponga en acción la homofobia, en tanto esta es un ejercicio constante entre los grupos de varones, y que termina afectando a quienes, por distintas razones, no la reproducen o la reproducen inadecuadamente según su grupo. En esta línea, Kimmel (1997) sostiene que la huida homofóbica de la intimidad con otros hombres es el repudio al homosexual que está dentro de sí, tarea que es constantemente revalidada en las relaciones entre varones, debido a que nunca es totalmente exitosa. Dicho de otra forma, la homofobia es un principio organizador de la masculinidad hegemónica.

Además, con respecto al riesgo y la violencia, Vásquez (2013) plantea que, mientras mayor sea el riesgo que se adopte, así como la violencia que se experimente, mayor será el capital masculino obtenido. De esta manera, por un lado, se añade al elemento de la homofobia el elemento de la violencia como un mecanismo válido y apropiado en la socialización, por lo cual la violencia homofóbica resulta ser un fenómeno no solo tolerado, sino fomentado en el camino de la obtención del capital masculino. Por otro lado, se reconoce el coraje y el miedo, mientras que el quejarse es asociado a lo femenino, que es rechazado. Por ende, ante un caso de violencia escolar, no resolverlo por uno mismo y acudir a otras personas en busca de ayuda sería desalentado al ir contra la masculinidad hegemónica. Esto hace posible que la dinámica de la violencia se reproduzca.

Así, en el contexto de la escuela peruana, se presenta la asociación entre homofobia, violencia y masculinidades. En dicha relación, las dos primeras no solo son toleradas, sino que constituyen parte fundamental del proceso de obtención de capital masculino y, de esta forma, en la construcción de una masculinidad reconocida por los otros como tal. Esta dinámica de construcción de masculinidades anclaría dichas prácticas de violencia y homofobia en los sujetos que, de alguna forma, se distancian de lo considerado masculino. Los chicos «afeminados» o que no encajan en lo valorado como masculino serían los más vulnerables a la violencia escolar por homofobia. La violencia homofóbica como un fenómeno principalmente masculino (en $77 \%$ de los casos) tiene sentido en tanto es parte del proceso de construcción de determinadas masculinidades. 
No obstante, si bien observamos que es un fenómeno eminentemente masculino, se aprecia que, también, un $23 \%$ de los casos corresponde a mujeres afectadas por la violencia homofóbica o, más precisamente, lesbofóbica. Lo interesante, en este caso, es que las exploraciones acerca de cómo funciona la lesbofobia o la homofobia hacia las jóvenes son limitadas. Esto revela la necesidad, como planteó Alfarache (2009), de estudiar y analizar cómo se construyen socialmente las (homo)sexualidades masculinas y femeninas de manera diferenciada, debido a que, en la generalidad, se invisibiliza la realidad específica de las mujeres que escapan a la heterosexualidad o a lo establecido como «femenino». Mientras que con la homofobia hacia los adolescentes varones hay teorías validadas sobre cómo interpretar dicho fenómeno, no sucede lo mismo con la homofobia hacia las adolescentes mujeres. Esto plantea una necesidad de estudios que profundicen en este fenómeno.

\subsection{Un fenómeno principalmente urbano}

Llama la atención que la violencia homofóbica en la escuela resulte ser un fenómeno asociado con el ámbito urbano, y que proviene de la costa y de la selva del país, y -más bien- está alejado de lo rural y de la sierra del país. En el gráfico 3, se observa que la proporción de afectados por violencia escolar nacidos en Lima-Callao versus aquellos nacidos en la sierra del país es similar, y es de 1 a 3 -respectivamente- en el caso de sus padres, diferencia generacional que se entiende por el proceso migratorio de las últimas décadas. Sin embargo, cuando observamos el lugar de nacimiento de los afectados por violencia homofóbica y de sus padres, notamos que la proporción de nacidos en Lima-Callao es mayor mientras que el porcentaje de nacidos en la sierra del país es menor.

Gráfico 3. Lugar de nacimiento de padres y de afectados por violencia homofóbica (VH) y por violencia en general (VG)

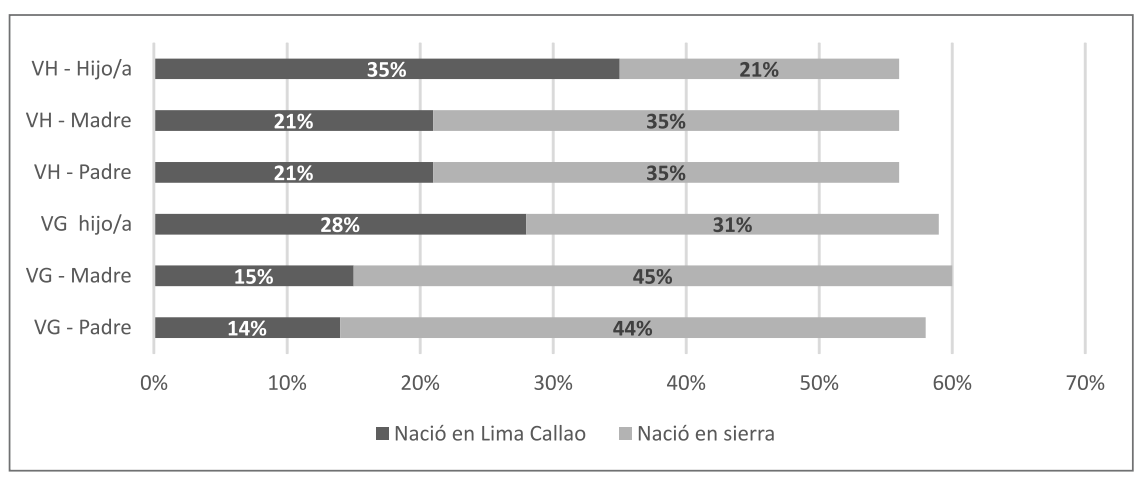

Fuente: Minedu (2013). Elaboración propia. 
Si bien no es en absoluto equiparable el provenir de la sierra o que los padres provengan de la sierra con el contexto rural, para esbozar una interpretación de esta relación entre escuela urbana de la costa del país y violencia homofóbica, se puede recoger lo planteado por Callirgos (1995) sobre la cultura escolar alternativa en Lima. El autor sostiene que, por un lado, la escuela oficial propone el ideal de joven estudioso y obediente, mientras que el modelo alternativo impulsa la figura del «achorado», el «vivo», el astuto, que incumple las normas, pero lo disimula para no ser sancionado, y también quien actúa con violencia, debido a que puede insultar y amedrentar a otros como forma de ser respetado. Callirgos explica esta cultura escolar desde el mandato de acriollamiento que se les ha exigido a las poblaciones de migrantes, quienes, a su vez, lo reproducirían en la siguiente generación como mandato de adaptación a la vida en la ciudad. Esto podría contribuir a explicar, de manera muy general, la asociación entre violencia escolar y ámbitos urbanos. De hecho, ForeroLondoño (2011) plantea que la violencia escolar, lejos de ser una desviación -en términos sociológicos-, constituye el régimen de visibilidad y de obtener reconocimiento en un contexto escolar en el que predominan los modelos autoritarios y el poco reconocimiento de la alteridad.

Ahora bien, con respecto a la homofobia y los contextos urbanos, René (2014) señala que usualmente se ha presentado a la ciudad como el ámbito idóneo para la construcción y la expresión de las sexualidades minoritarias. Sin embargo, es necesario tener en cuenta que «la urbanización, el anonimato, la distancia social y la homosexualidad surgieron y se construyeron juntos como manifestaciones de la modernidad» (René, 2014). Así, en medio del pluralismo de formas de clase, étnicas y culturales, se abre paso la posibilidad de expresiones sexuales y de género diversas (Weeks, 1998, p. 81), pero también la vulnerabilidad a la violencia. Por eso, René sostiene que los espacios de homosocialización en las ciudades se construyen a partir de la angustia; el silencio; la soledad; y, sobre todo, la fragmentación, en que el estigma y la discriminación establecen estrategias socioespaciales (el gueto, el clóset, etc.) destinadas a evitar el peligro. Es decir, en la ciudad, si bien surge la posibilidad de ser diverso, la expresión pública de esta diversidad es sancionada, a veces, de manera fatal. De este modo, diversidad y violencia conviven en la dinámica urbana.

Con ello, podríamos plantear que la escuela urbana sería un escenario de mayor violencia, incluso cuando se trata de violencia escolar en general. Esto se debe, en parte, a que es un espacio que, a pesar de la diversidad inherente a ella, no logra procesarla con integración, en tanto hay expresiones hegemónicas, y expresiones que son relegadas y subordinadas. El mandato de acriollamiento en un contexto particular como las grandes ciudades de la costa del Perú, sumado a la regulación social de las expresiones sexuales y de género no hegemónicas que en los espacios públicos de la urbe operan, podrían explicar la relación encontrada entre violencia homofóbica y escuela urbana. Es decir, en los ámbitos urbanos, las diversidades sexuales y de género son reprimidas tanto por desafiar la heteronormatividad como por ser en sí misma una 
forma de diversidad. Esta es una de las hipótesis que valdría la pena explorar en trabajos sobre la violencia homofóbica desde metodologías cualitativas que profundicen en los sentidos que se ponen en juego.

\subsection{Manifestaciones de la violencia homofóbica}

Al explorar cómo ocurre la violencia escolar, según el tipo de agresor, el lugar de la agresión y las formas de agresión, se encuentra lo siguiente. En primer lugar, existen diferencias entre las manifestaciones de la violencia en función del tipo de agresor. Cuando el agresor es otro alumno (gráfico 4), la agresión se da mediante insultos, golpes, burlas e insultos por medios electrónicos. Los porcentajes en que la violencia escolar en general proviene de otros alumnos son altos: aproximadamente, 3 de 4 han recibido insultos de sus compañeros, y casi la mitad han recibido golpes, burlas y -en menor medida (37\%)- insultos por medios electrónicos. Sin embargo, cuando se analiza a la población afectada por violencia homofóbica, los porcentajes son considerablemente más altos. Se observa que más del $80 \%$ de los afectados por violencia homofóbica han sido insultados por sus compañeros, el $60 \%$ han sido golpeados por algún compañero, y más de la mitad han sido objeto de burlas o de insultos por medios electrónicos. Esto significa que la incidencia de agresiones en sus distintas formas es mayor en la población afectada por violencia homofóbica que en el resto de población afectada por violencia escolar. Se trata, entonces, de una violencia que, cuando proviene de otros alumnos, es más agresiva, y, por ende, tiene otras características y dinámicas.

Asimismo, en los casos en que los agresores son adultos en la escuela (docentes, autoridades, personal en general), se observa que, entre los afectados por violencia homofóbica, hay mayor porcentaje de insultos (32\%) y burlas (28\%) que entre los afectados por violencia escolar en general. En ese sentido, la violencia homofóbica también es más agresiva que otras formas de violencia escolar cuando proviene de adultos en la escuela. Con respecto a ello, algunos autores han explorado cómo los profesores tienen creencias y actitudes homofóbicas. Quaresma et al. (2013, p. 446) señalan en una investigación en escuelas brasileñas que el $25 \%$ de profesores califican la homosexualidad y transexualidad como una anomalía que debe ser corregida, mientras que Penna y Sánchez (2015) afirman que un 20\% de los futuros profesores en Ecuador manifiesta actitudes homofóbicas. Por ello, se considera que la violencia escolar es solo una de las formas en que se expresa la homofobia, la cual está bastante más anclada en un sistema de género; en pautas que regulan las instituciones y las relaciones sociales; y que definen lo normal y lo anormal, lo deseable y lo repudiable (Lozano \& Rocha, 2011). 
Gráfico 4. Forma de agresión según tipo de agresor

Forma de agresión cuando el agresor es otro alumno

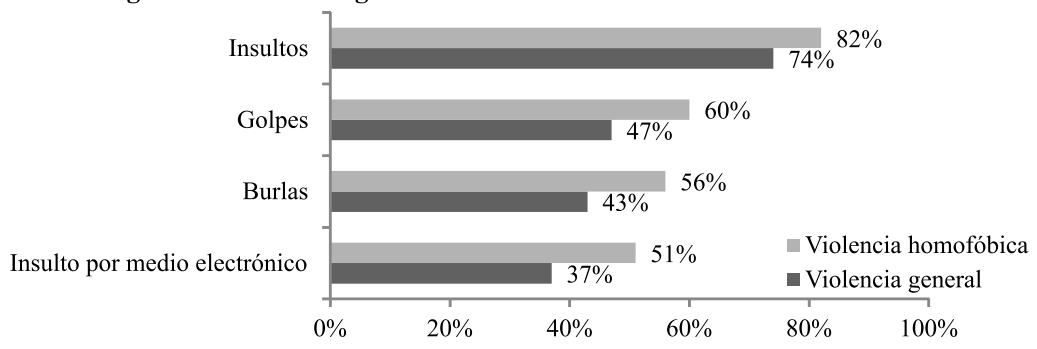

Forma de agresión cuando el agresor es un adulto

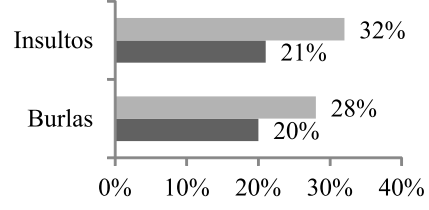

Fuente: Minedu (2013). Elaboración propia.

Con respecto al lugar en que ocurre la agresión, se ha encontrado que la violencia suele ocurrir en el aula, tanto cuando se trata de violencia en general (57\%) como cuando se trata de violencia homofóbica (67\%), lo que evidencia que los actos son practicados en la presencia del adulto responsable del grupo (Prodócimo et al., 2014). Lo que llama la atención es cómo la violencia homofóbica se produce con mayor frecuencia que la violencia en general en el patio; en los alrededores del colegio; y, sobre todo, en los baños, donde el porcentaje se triplica (18\%) en los casos de violencia homofóbica. Se observa que en el caso de la violencia homofóbica ningún espacio de la escuela resulta seguro, puesto que, hasta en aquellos espacios que podrían ser un poco más seguros para el resto de las personas, como el baño y el patio, la manifestación de violencia homofóbica es, también, alta. Sin intentar explicar cómo ocurre la violencia homofóbica en cada lugar señalado, resulta interesante cómo el baño es un espacio en que se da casi la quinta parte de casos de violencia homofóbica. Retomamos, para ello, lo planteado por Kimmel (1997) sobre cómo las prácticas de construcción de la masculinidad tienen como contexto de reproducción los espacios homosociales. Sobre esta base, encontramos que el baño (que, en la mayoría de casos, es segregado por sexo) reúne las condiciones de ser un espacio homosocial y de estar relativamente fuera de la vigilancia de las autoridades u otros actores, por lo cual sería un espacio en que la homofobia es recurrente. 
Gráfico 5. Lugar de la agresión

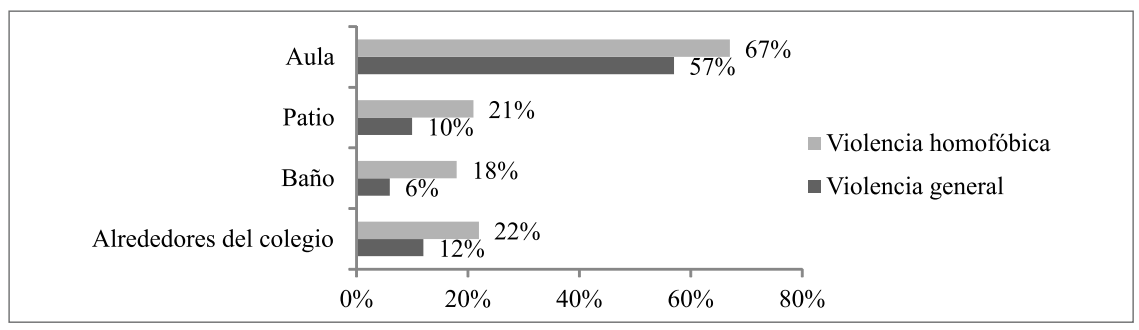

Fuente: Minedu (2013). Elaboración propia.

Al explorar las formas de agresión que declaran haber sufrido ambas poblaciones, se nota una diferencia considerable en el caso de tocamientos indebidos (gráfico 6). Así, mientras el $16 \%$ de afectados por violencia escolar ha sido víctima de tocamientos indebidos, cifra que ya es preocupante, entre los afectados por violencia homofóbica, este porcentaje aumenta a 36\%. Es decir, más de la tercera parte de afectados por violencia homofóbica ha sido víctima de tocamientos indebidos, lo que se constituye como una forma de violencia sexual.

\section{Gráfico 6. Tocamientos indebidos}

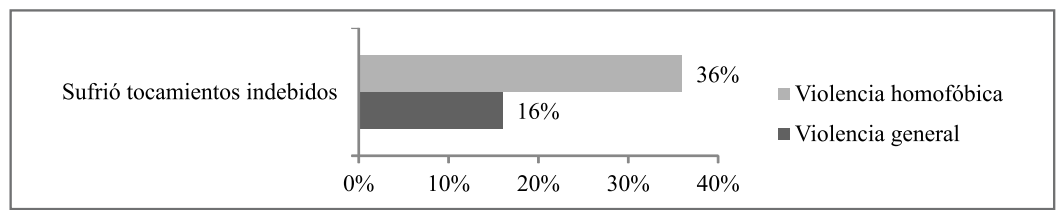

Fuente: Minedu (2013). Elaboración propia.

Otro dato muy preocupante que da cuenta de cómo llega a operar la violencia en la escuela es que, al preguntar por haber sido obligado por un compañero de colegio a tener relaciones sexuales, el $4,1 \%$ de afectados por violencia escolar en general responde afirmativamente. Cifra que asciende a $8,8 \%$ en el caso de los afectados por violencia escolar homofóbica. En otras palabras, el ser víctima de violación sexual por parte de un compañero de colegio es el doble de probable cuando se es afectado por violencia escolar homofóbica que cuando se es afectado por violencia escolar en general. 
Gráfico 7. Violación sexual por parte de otro alumno

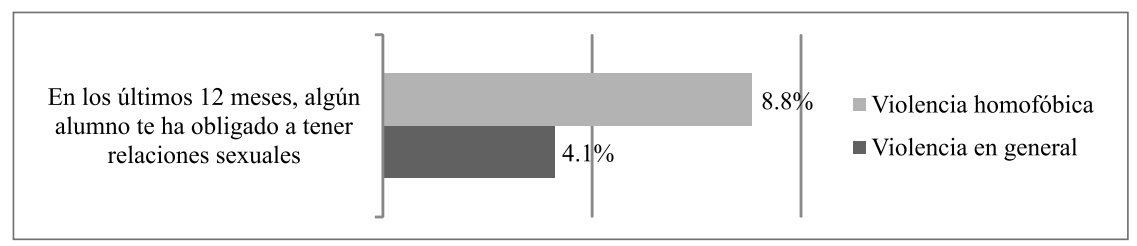

Fuente: Minedu (2013). Elaboración propia.

$\mathrm{Al}$ analizar las manifestaciones de la violencia homofóbica y de la violencia en general de manera diferenciada, observamos que, en el caso de violencia homofóbica, hay mayor incidencia de agresiones tanto cuando proviene de otros alumnos como de adultos en la escuela; además, se produce con frecuencia en los distintos espacios de la escuela y la incidencia de abuso sexual (tocamientos indebidos y violación sexual) es mucho mayor en esta población que en otras afectadas por violencia escolar. Por eso, afirmamos que se trata de un tipo de violencia escolar que hostiga de manera más sistemática a sus víctimas y a través de diferentes mecanismos, entre ellos, específicamente, el de la violencia sexual.

\subsection{Violencia homofóbica y clima escolar}

En su estudio sobre la relación entre la ideación suicida y los factores protectores escolares, Withaker et al. (2015) abordan los factores protectores como las características y los recursos que reducen el riesgo de ideación suicida en adolescentes lesbianas, gays y bisexuales. Estos factores protectores se relacionan con el nivel de soporte emocional que tiene la persona, la cohesión de sus relaciones sociales más cercanas, etc.

En la escuela, se trataría de un adecuado clima escolar como el principal factor protector. Como plantean Flores-González et al. (2011), en un clima escolar positivo, los acontecimientos de crisis son más fáciles de gestionar. El clima escolar, al ser fruto de la percepción colectiva del ambiente escolar, está definido por la percepción que tienen los miembros de la escuela acerca de si son respetados por la comunidad educativa, y, en el caso de los estudiantes, el nivel de confianza que tienen en el soporte de los adultos y de las autoridades de la escuela.

$\mathrm{Al}$ analizar la percepción que tienen los estudiantes sobre la escuela, se observa que las percepciones positivas son, en general, la mayoría. Sin embargo, reiteradamente, en lo que respecta a los estudiantes afectados por violencia escolar en general, aquellos afectados por violencia homofóbica tienen una menor percepción de la escuela como un espacio justo, en el que se respeten las diferencias y, específicamente, al propio estudiante (gráfico 8). 
Gráfico 8. Percepción del estudiante sobre el clima escolar

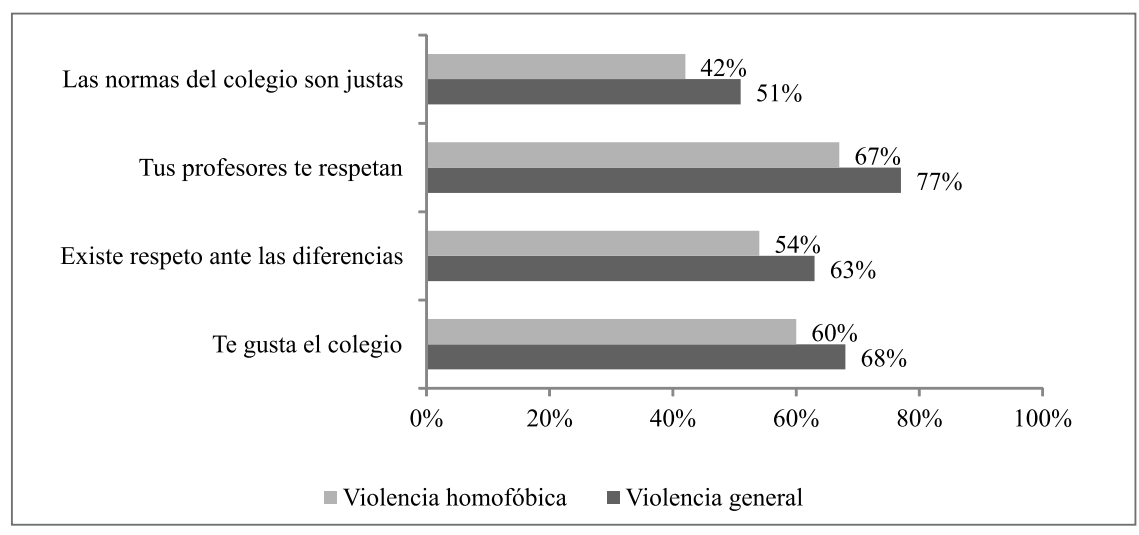

Fuente: Minedu (2013). Elaboración propia.

La menor percepción de buen clima escolar que hay entre los afectados por violencia homofóbica significa que, en esta población, los factores protectores escolares son incluso menores que entre los afectados por violencia en general, lo cual, siguiendo a Withaker et al. (2015), incrementa el riesgo de que estos estudiantes presenten ideación suicida $\mathrm{u}$ otros problemas asociados a la violencia. Como plantea Pacheco-Salazar (2015), la no atención a la diversidad es un factor de riesgo y una expresión de violencia simbólica por parte de la escuela. Esto plantea la necesidad de fomentar una cultura de justicia y de respeto de la diversidad en la escuela; específicamente, de respeto a las diversidades sexuales y de género. De este modo, se contribuiría, por un lado, a combatir la violencia homofóbica y, por otro, a proteger a los estudiantes que son afectados por este tipo de violencia, en tanto el respaldo de la institución escolar es clave para la atención de estos casos.

\subsection{Impacto de la violencia en el bienestar subjetivo}

Con bienestar subjetivo nos referimos a «las percepciones, evaluaciones y aspiraciones, positivas o negativas, que las personas tienen sobre sus vidas» (Oyanedel, 2015), lo que está íntimamente relacionado con la satisfacción vital y el bienestar personal. En esta línea, el bienestar subjetivo de los estudiantes da cuenta del nivel de satisfacción que sienten estos con sus vidas.

$\mathrm{Al}$ ser este un aspecto particularmente importante -usualmente la preocupación central cuando nos referimos a violencia hacia niños, niñas y adolescentes-, se ha decidido incluir en este apartado las respuestas de la población encuestada en general. De este modo, se puede comparar al total de estudiantes con las respuestas de aquellos afectados por violencia escolar en general y con aquellos afectados por violencia escolar homofóbica. 
Al preguntar a los estudiantes si consideraban que su vida es excelente, mientras que un $18 \%$ del total responde que no, este porcentaje aumenta a $22 \%$ en el caso de los afectados por violencia en general y, en el caso de los afectados por violencia homofóbica, asciende a un $28 \%$. Esto se traduce en una mayor negatividad en la evaluación sobre la propia vida en el caso de los estudiantes afectados por violencia escolar e incluso mayor negatividad en el caso de los estudiantes afectados por violencia escolar homofóbica.

Gráfico 9. Apreciación negativa sobre la propia vida

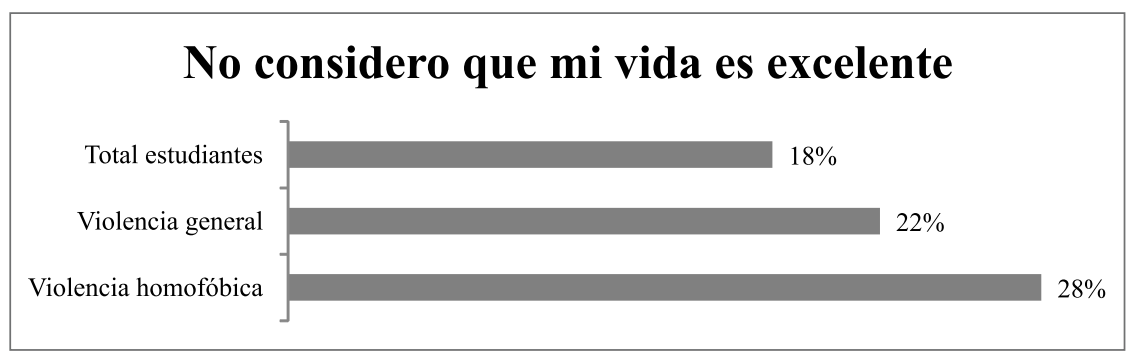

Fuente: Encuesta de Convivencia Escolar (2013). Elaboración propia.

Gráfico 10. Apreciación positiva sobre el propio cuerpo

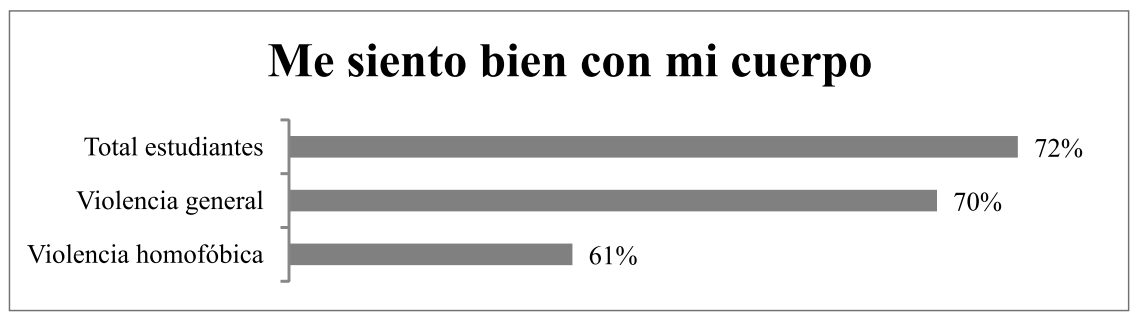

Fuente: Encuesta de Convivencia Escolar (2013). Elaboración propia.

Por otro lado, al preguntar por si se sentían bien con su cuerpo, el $72 \%$ de estudiantes respondió que sí («SÍ » y «iSí!»), lo mismo que el 70\% de afectados por violencia en general, pero esta cifra se reduce a un $61 \%$ en el caso de los afectados por violencia homofóbica. Es decir, mientras que la proporción de estudiantes satisfechos con su cuerpo entre el total de estudiantes y los afectados por violencia en general difiere por poco (2\%), la diferencia con respecto a los estudiantes afectados por violencia homofóbica sí es considerable. En relación con este punto, podríamos sugerir que esta menor conformidad con el cuerpo podría relacionarse con que, como hemos visto en acápites anteriores, la violencia homofóbica resulta más agresiva al recaer sobre el cuerpo de los afectados. Así como en los afectados por violencia homofóbica hay una 
mayor proporción de violencia física (golpes) y violencia sexual (tocamientos indebidos y violación sexual) -ambas expresiones de violencia que vulneran el cuerpo directamente-, habría, también, un mayor impacto en la percepción y evaluación del propio cuerpo. De alguna forma, en las dinámicas que se producen por la homofobia, la relación entre aquello que es violentado (sean expresiones de género no hegemónicas o expresiones homoeróticas) y el cuerpo de la víctima parece ser más estrecha. El cuerpo resulta tanto objeto de la violencia como una materialidad menos valorada por la persona violentada. Pareciera ser que la violencia homofóbica, particularmente, encuentra en el cuerpo un lugar al cual asirse, tanto por los agresores -quienes lo agreden más intensamente- como por los agredidos -quienes se sienten menos conformes con su propio cuerpo-.

En todo caso, la encuesta muestra que, en efecto, el bienestar subjetivo de los estudiantes afectados por violencia homofóbica está más deteriorado que el bienestar subjetivo de los estudiantes afectados por violencia escolar en general. En la línea de lo planteado por Penna (2015), el acoso por homofobia genera sufrimiento psíquico, incluidos el miedo y la conducta suicida, que, a su vez es una condición que posibilita diversas prácticas de riesgo y conductas (auto) destructivas. Asimismo, García y Ascensio (2015) recuerdan que la naturalización de la violencia homofóbica por parte del medio social, e incluso por la propia persona afectada, se puede convertir en un contexto moral y psicológico que instaura un código de silencio en torno a la violencia, reproduciéndola y/o intensificándola.

\subsection{Problemas asociados a la violencia escolar}

En este apartado, exploramos tres tipos de fenómenos que suelen estar asociados a la violencia escolar, específicamente, cómo se dan estos entre los afectados por violencia homofóbica.

\section{Violencia familiar y en relaciones de pareja}

Distintos autores han estudiado la relación entre la violencia escolar y la violencia en el ámbito familiar. Al respecto, García y Ascensio (2015) señalan que los modelos familiares violentos favorecen la violencia en otros ámbitos, puesto que es la familia la primera instancia que proporciona a la persona un conjunto de modelos socioculturales, y mecanismos para afrontar los conflictos y procesar las diferencias. Además, Valdés y Martínez (2014) plantean que, entre las variables que explican la violencia escolar, se encuentran el clima escolar y familiar. A partir de ello, en este estudio, exploramos la prevalencia de la violencia en el ámbito familiar y en las relaciones de pareja. Los resultados obtenidos muestran que el $20 \%$ de afectados por violencia escolar, en general, han sido víctimas de una forma de violencia familiar reciente, mientras que entre los afectados por violencia homofóbica esta cifra asciende a $25 \%$. De esta 
forma, se observa que hay mayor prevalencia de violencia familiar en los estudiantes afectados por violencia homofóbica que en los afectados por violencia escolar en general.

Gráfico 11. Manifestación reciente de violencia familiar

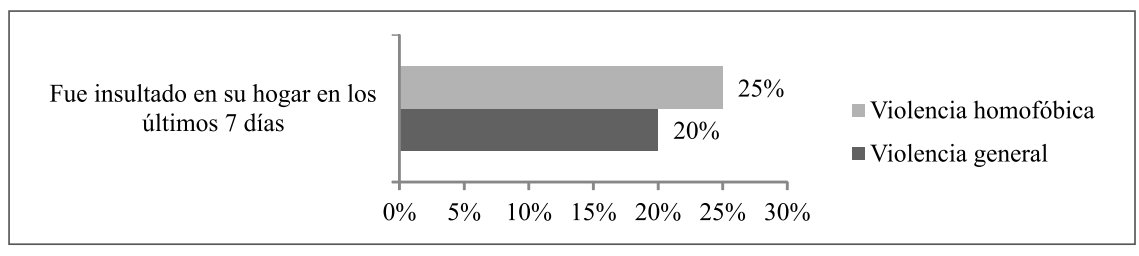

Fuente: Encuesta de Convivencia Escolar (2013). Elaboración propia.

$\mathrm{Al}$ analizar las relaciones de pareja, la encuesta permite indagar en una dinámica particular: la de la víctima que es a la vez agresor. Así, encontramos que entre el $3 \%$ y $4 \%$ de los afectados por violencia escolar declaran haber forzado a sus parejas a tener relaciones sexuales y a haber sido forzados por sus parejas a tener relaciones sexuales. Es importante notar que, en la mitad de estos casos, la persona ha forzado a su pareja y, simultáneamente, ha sido forzada por su pareja a mantener relaciones sexuales; en la otra mitad, la persona se declara solo agresora o solo agredida. En todo caso, estos casos no superan el $4 \%$, que de por sí es una cifra preocupante si tenemos en cuenta que se está aludiendo a violación sexual en la relación de pareja. No obstante, entre el grupo de afectados por violencia homofóbica, esta cifra asciende a $8 \%$ (quienes forzaron a su pareja) y a $10 \%$ (quienes fueron forzados por su pareja); es decir, la prevalencia de violencia sexual en las relaciones de pareja (como víctima y como agresor) corresponde a más del doble entre los estudiantes afectados por violencia homofóbica que entre los estudiantes afectados por violencia escolar en general.

Gráfico 12. Violencia sexual en relaciones de pareja

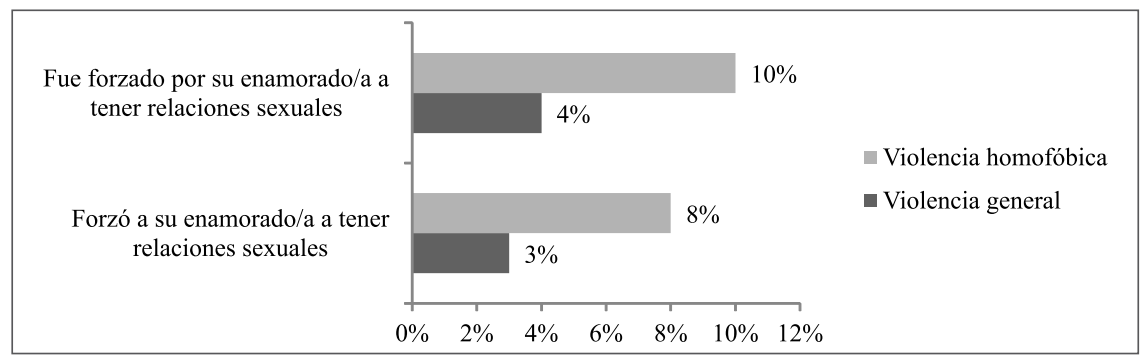

Fuente: Encuesta de Convivencia Escolar (2013). Elaboración propia. 
A continuación, nos adentramos en la dinámica del agredido que es a la vez agresor, sobre la cual la encuesta planteó solo dos preguntas. Observamos en el gráfico 13 que, al preguntarles a los estudiantes si en el último mes golpearon a alguien en el colegio con un objeto, el $24,4 \%$ del total de estudiantes responden que sí. Esta cifra se eleva a $35,8 \%$ en el caso de los afectados por violencia escolar en general, y es de $43,3 \%$ entre los afectados por violencia escolar homofóbica. Estos resultados, lejos de estigmatizar a los estudiantes afectados por violencia escolar o, peor aún, justificar que sean agredidos, deben llamar la atención sobre cómo se está comprendiendo el fenómeno de la violencia escolar, sobre todo, cuando se da entre pares. En este sentido, es vital comprender que la violencia se constituye como un componente de determinadas relaciones sociales en la escuela y no como una acción unidireccional de agresores a víctimas. Entre estas relaciones sociales específicas, estarían las de pares (especialmente, pares varones), las de profesor-estudiante, las de autoridad-estudiante, etc. Si bien puede haber estudiantes que ocupan más sistemáticamente la posición de víctima o agresor, muchas veces, cuando la víctima no encuentra cómo detener la violencia, una forma de reaccionar es involucrarse activamente en la dinámica de violencia en tanto agresor. Tal y como sostuvo Vásquez (2013), la agresión al otro mediante la homofobia y la feminización suelen ser una acción en cadena. Este autor lo llama «el juego de la papa caliente», en el cual, el adolescente, si no quiere caer en el rol del agredido sistemáticamente («el punto»), debe pasar la agresión hacia otro compañero. Asimismo, de ninguna manera, debe acudir con las autoridades, puesto que ello lo dejaría en una situación más vulnerable. Una política escolar que busque reducir la violencia debe tener claro cómo esta funciona para así implementar mecanismos adecuados dentro de la escuela para procesar los conflictos, y afrontar los casos de agresiones y de violencia estructural.

Gráfico 13. Golpeó a alguien en el colegio con un objeto

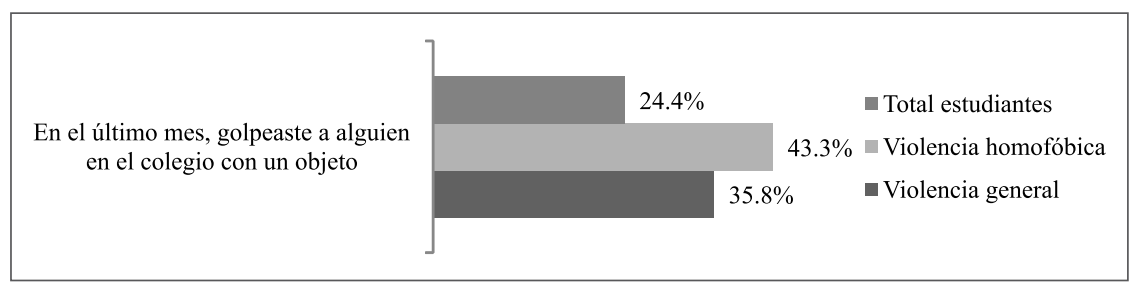

Fuente: Encuesta de Convivencia Escolar (2013). Elaboración propia.

Se considera que podríamos estar ante un patrón de violencia en la sociabilidad de los estudiantes afectados por la violencia escolar y, específicamente, afectados por la violencia homofóbica. Esto guardaría relación con la violencia que se manifiesta en la escuela y la violencia en la familia, así como con la prevalencia de afectados por violencia que a la vez son agresores. 
Asimismo, si entendemos la homofobia como un fenómeno no propiamente del ámbito escolar, sino más bien un fenómeno social, enmarcado en las relaciones de género que se construyen en sociedad, podemos afirmar que es muy probable que los estudiantes que son afectados por violencia homofóbica en la escuela también sufran este tipo de violencia en sus hogares. La naturalización de la violencia en las relaciones sociales más próximas y la interiorización de la homofobia podrían tentarse como hipótesis para explicar la alta prevalencia de violencia sexual en las relaciones de pareja, en las que la persona se reconoce tanto agresor como víctima.

\section{Consumo de alcohol y drogas}

Otro de los fenómenos que suelen estar asociados a la violencia, como consecuencia de esta, es el consumo de drogas y de alcohol (Cano et al., 2009, p. 179), los cuales pueden ser usados por quienes los consumen como formas de escapar a una realidad que no se sienten capaces de procesar. En la encuesta analizada, se preguntó por el consumo de estas sustancias dentro de las instalaciones del colegio y su frecuencia. A partir de ello, se encontró que el 4\% de afectados por violencia escolar ha consumido alcohol en el colegio más de una vez. Esta cifra se duplica en el caso de los afectados por violencia homofóbica. De modo similar, el $2 \%$ de afectados por violencia escolar declara haber consumido drogas en el colegio más de una vez, cifra que asciende a $5 \%$ en el caso de los afectados por violencia homofóbica. Si bien se trata aún de cifras menores, el hecho de que se trate de un consumo reiterado (más de una vez) de estas sustancias y en el colegio revela que el problema puede ser más extendido. Además, vemos nuevamente que, tanto en lo que respecta a consumo de drogas como de alcohol, la prevalencia del consumo es el doble o más en el caso de los afectados por violencia homofóbica frente a aquellos afectados por violencia escolar en general.

Gráfico 14. Consumo de alcohol y drogas en el colegio

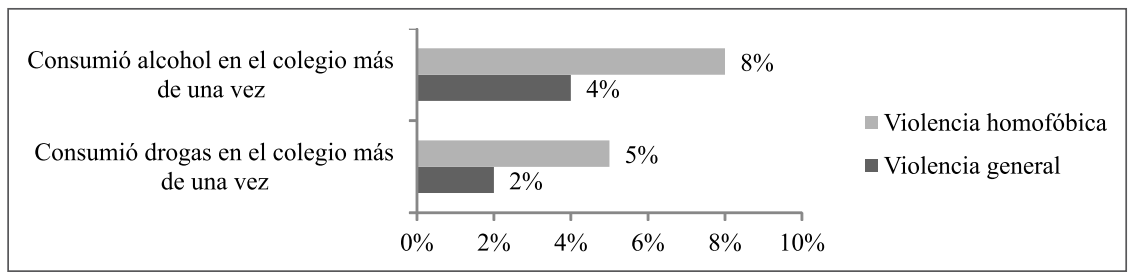

Fuente: Minedu (2013). Elaboración propia. 


\section{Ausentismo y bajo rendimiento}

El ausentismo escolar y el bajo rendimiento, también, son problemas asociados con la violencia escolar (Román \& Murillo, 2011; García \& Ascensio, 2015). Al preguntar a los estudiantes sobre si bajaron sus notas luego de sufrir alguna agresión en la escuela, el 12\% de los afectados por violencia escolar declararon que sí, que ese fue un efecto de la agresión. Entre los afectados por violencia homofóbica, esta cifra es mayor: alcanza el 19\%, lo que quiere decir que casi 1 de cada 5 afectados por violencia homofóbica disminuyó sus notas como consecuencia de esta violencia. A diferencia de otras formas de violencia, la violencia homofóbica tiene un mayor impacto en el rendimiento escolar de sus víctimas.

Asimismo, de los afectados por violencia escolar en general, el 11\% manifiesta haber faltado al colegio por temor a ser agredido, cifra que se eleva a $16 \%$ en el caso de los afectados por violencia homofóbica. Nuevamente, se observa que el impacto de la violencia homofóbica en sus víctimas, al punto de faltar a clases por temor a futuras agresiones, es mayor que otros tipos de violencia escolar.

Gráfico 15. Ausentismo y bajo rendimiento producto de la violencia

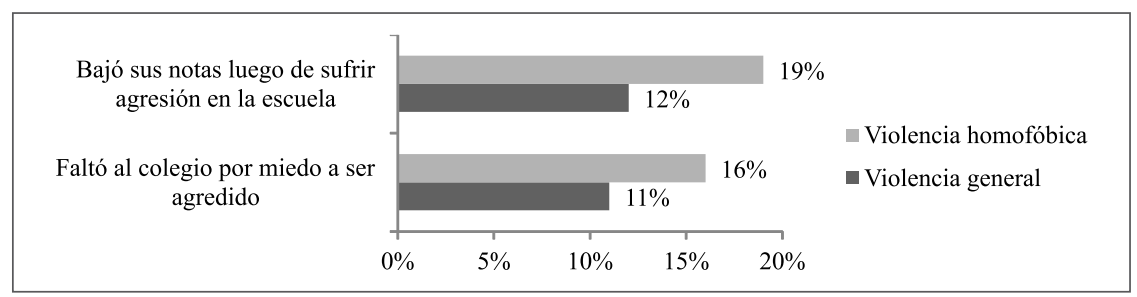

Fuente: Minedu (2013). Elaboración propia.

Mediante el análisis de la violencia en relaciones de pareja y dentro de la familia, el consumo de alcohol y drogas, y el ausentismo y bajo rendimiento escolar como consecuencias de la violencia escolar, sostenemos que la población de estudiantes afectados por violencia homofóbica resulta una población más vulnerable a problemas asociados a la violencia.

\section{Conclusiones}

Si bien la violencia homofóbica en la escuela es un tipo de violencia escolar, el presente estudio da cuenta de que su dinámica tiene particularidades que hacen necesaria una aproximación específica y a profundidad de dicho fenómeno. En primer lugar, se ha encontrado relación entre ser afectado por violencia homofóbica, y ser hombre y estudiar en escuelas urbanas, por lo que 
sostenemos que la violencia escolar homofóbica se perfila como un fenómeno principalmente masculino y urbano. La violencia homofóbica hacia aquellos estudiantes que muestran prácticas o expresiones consideradas femeninas sería parte constitutiva del proceso de construcción de masculinidades en la escuela. Mientras que, en el ámbito urbano, si bien conviven mayor diversidad de expresiones, operan ciertos mandatos que jerarquizan y/u homogenizan dichas diversidades; entre estas, la regulación social de las expresiones sexuales y de género no hegemónicas en los espacios públicos y virtuales. Sin embargo, queda pendiente empezar a explorar bajo qué lógicas opera la violencia homofóbica en las escuelas rurales, y en los casos en que las afectadas son niñas o adolescentes mujeres.

En segundo lugar, al analizar sus manifestaciones, la violencia escolar por homofobia hostiga de manera más sistemática a sus víctimas que otros tipos de violencia. La incidencia de violencia sexual entre afectados por violencia homofóbica es el doble que entre los afectados por violencia en general. Más de la tercera parte de afectados por violencia homofóbica ha sido víctima de tocamientos indebidos.

En tercer lugar, se observa que los afectados por violencia homofóbica tienen menor percepción de buen clima escolar, y están menos satisfechos con su cuerpo y su vida que los afectados por violencia escolar en general. Esto tendría relación con la mayor incidencia de agresión y violencia sexual que se ejerce sobre este grupo.

En cuarto lugar, los estudiantes afectados por violencia escolar homofóbica resultan una población más vulnerable a problemas como el consumo de alcohol y drogas; el ausentismo y el bajo desempeño escolar; y el ser parte (víctima/agresor) de relaciones violentas en otros entornos, como el hogar y la pareja. Esto podría estar asociado con la falta de apoyo, o incluso victimización múltiple, en distintos ámbitos cuando se trata de prácticas homofóbicas que suelen ser naturalizadas. Asimismo, puede vincularse con el menor bienestar subjetivo, que suele ser una condición que posibilita prácticas de riesgo y conductas destructivas y autodestructivas.

Estos resultados plantean la necesidad de seguir indagando en la violencia homofóbica como un fenómeno que atraviesa todas las relaciones sociales, entre ellas, las que tienen lugar en la escuela. Del mismo modo, se hace necesario y urgente fomentar una cultura de respeto de la diversidad en la escuela, específicamente de respeto a las diversidades sexuales y de género. Esto contribuiría, por un lado, a combatir la violencia homofóbica y, por otro, a proteger a los estudiantes que son afectados por este tipo de violencia, en tanto el respaldo de la institución escolar es clave para la atención de estos casos. 


\section{Nota biográfica}

\section{Lucero Cuba Varas}

Es socióloga y estudiante de la Maestría de Estudios de Género de la Pontificia Universidad Católica del Perú. Investiga temas de género, educación y diversidad sexual. Ha trabajado en evaluación y políticas educativas en el Ministerio de Educación y, a la fecha, en el Centro de Medición, Evaluación y Certificación de la PUCP.

\section{TOMÁs Osores GonzÁLES}

Es sociólogo y magíster en Territorios, Espacios, Sociedades por la EHESS. Investiga temas de pobreza multidimensional contextos peruanos y focalización en la Dirección de Diseño de Investigación, del Ministerio de Desarrollo e Inclusión Social. 


\section{Referencias}

Alfarache, A. (2009). Las mujeres lesbianas y la antropología feminista de género. Recuperado de http://www.caladona.org/grups/uploads/2009/08/ las-mujeres-lesbianas-y-la-antropologia-feminista-de-genero-aalfarache.pdf

Bourdieu (1999). Razones prácticas. Sobre la teoría de la acción, $2^{a}$ edic. Barcelona: Anagrama

Amemiya, I., Oliveros, M. \& Barrientos, A. (2009, diciembre). Factores de riesgo de violencia escolar (bullying) severa en colegios privados de tres zonas de la sierra del Perú. Anales de la Facultad de Medicina [en línea], $70(4), 255-258$.

Butler, J. (2001). El género en disputa: El feminismo y la subversión de la identidad. México D.F.: Editorial Paidós.

(2002). Cuerpos que importan. Sobre los límites materiales y discursivos del «sexo». Buenos Aires: Paidós.

Cáceres, C. F., Salazar, X. (Eds.) (2013). «Era como ir todos los días al matadero...» El bullying homofóbico en instituciones educativas públicas en Chile, Guatemala y Perú (documento de trabajo). Lima: IESSDEH / UPCH / PNUD / Unesco.

Callirgos, J. C. (1995). La discriminación en la socialización escolar (separata). Lima: Fondo Editorial de la Pontificia Universidad Católica del Perú.

Cano, P., Gutiérrez, C. \& Nizama, M. (2009). Tendencia a la violencia e ideación suicida en adolescentes escolares en una ciudad de la Amazonía peruana. Revista Peruana de Medicina Experimental y Salud Pública, 26(2), 175-81.

Comisión Interamericana de Derechos Humanos (2015). Violencia contra Personas Lesbianas, Gays, Bisexuales, Trans e Intersex en América [Informe]. OEA/Ser.L/V/II. Doc. 36. Consulta: 25 de marzo de 2017. http://www.oas.org/es/cidh/informes/pdfs/violenciapersonaslgbti.pdf

Connell, R. W. (2011, abril). Educando a los muchachos: Nuevas investigaciones sobre masculinidad y estrategias de género para las escuelas. Nómadas (14), 156-171 Universidad Central Bogotá.

Del Castillo, D. (2001). Los fantasmas de la masculinidad. En S. López, G. Portocarrero, R. Silva Santisteban, V. Vich (Eds.), Estudios Culturales: discursos, poderes, pulsiones (pp. 253-264). Lima: Red para el Desarrollo de las Ciencias Sociales.

Espinosa, G. (2004, diciembre). Currículo y equidad de género en la primaria: Una mirada desde el aula. Estudio realizado en tres escuelas estatales de la ciudad Lima. En M. Benavides (Ed.), Educación y procesos pedagógicos y equidad. Cuatro informes de investigación (pp. 69-129). Lima: Grupo de Análisis para el Desarrollo (Grade). 
Forero-Londoño, O. F. (2011). La violencia escolar como régimen de visibilidad. Magis, Revista Internacional de Investigación en Educación, Edición especial «La violencia en las escuelas», 4(8), 399-413.

Flores-González, L. M. \& Retamal-Salazar, J. A. (2011). Clima escolar y gestión compleja del conocimiento: Desafíos para la investigación educativa y la política pública en violencia escolar. Magis. Revista Internacional de Investigación en Educación, Edición especial «La violencia en las escuelas», 4(8), 319-338.

García, M. \& Ascensio, C. (2015, julio-diciembre). Bullying y violencia escolar: Diferencias, similitudes, actores, consecuencias y origen. Revista Intercontinental de Psicología y Educación, 17(2), 9-38.

Instituto de Estudios Peruanos (2016). La ciudadanía desde la escuela: Vivir en el Perú. Serie Miscelánea, volumen 38. Lima: Instituto de Estudios Peruanos / Fundación Gustavo Mohme Llona.

Kimmel, M. (1997). Homofobia, temor, vergüenza y silencio en la identidad masculina. En T. Valdes \& J. Olavarría (Eds.), Masculinidad/es: Poder y crisis (pp. 49-62), Santiago: Isis Internacional, Ediciones de las Mujeres $\mathrm{N}^{\circ} 24$.

Lozano, I. \& Rocha, T. (2011). La homofobia y su relación con la masculinidad hegemónica en México. Revista Puertorriqueña de Psicología, vol 22, pp. 101-121.

Ministerio de Educación (2013). Encuesta de Convivencia Escolar 2013. Lima: Ministerio de Educación del Perú.

(2014). Paz Escolar: Estrategia Nacional contra la Violencia Escolar (2013-2016) (2 edición). Lima: Ministerio de Educación del Perú.

(2017). Sobre la violencia escolar en el Perú. Número de casos reportados en el SíseVe a nivel nacional (del 15 de setiembre de 2013 al 30 junio de 2017). Síse ve. Contra la violencia escolar. Recuperado de http://www.siseve.pe/Seccion/Estadisticas

Mollericona, J., Copa, J. \& Cadena, M. (2011). «Paradorcito eres, ¿no?». Radiografía de la violencia escolar en La Paz y El Alto. La Paz: Fundación PIEB.

Morgade, G. (Comp.) (2011). Toda educación es sexual: Hacia una educación sexuada justa. Buenos Aires: La Crujía.

Morgade, G. \& Alonso, G. (Comps.) (2008). Cuerpos y sexualidades en la escuela. De la «normalidad» a la disidencia. Buenos Aires: Paidós.

Oliveros, M. \& Barrientos, A. (2007). Incidencia y factores de riesgo de la intimidación (bullying) en un colegio particular de Lima-Perú, 2007. Revista Peruana de Pediatría, 60(3), 150-155. 
Oliveros, M., Figueroa, L., Mayorga, G., Cano, B., Quispe, Y. \& Barrientos, A. (2008). Violencia escolar (bullying) en colegios estatales de primaria en el Perú. Revista Peruana de Pediatría, 61(4), 215-220.

Ortiz-Hernández, L. \& García, M. I. (2005). Efectos de la violencia y la discriminación en la salud mental de bisexuales, lesbianas y homosexuales de la Ciudad de México. Cadernos de Saúde Pública, 21(3), 913-925.

Oyanedel, J. C. (2015). Violencia escolar y bienestar subjetivo infantil [diapositiva]. Consulta: 15 de marzo de 2017. http://www.ijvs.org/files/ JC-Oyanedel-_-Violencia-Escolar-y-Bienestar-subjetivo-infantil.pdf

Pacheco, B. (2015). Reflexiones sobre la no atención a la diversidad como violencia de la escuela. Ciencia y Sociedad, 40(4), 663-684.

Penna, M. (2015). Homofobia en las aulas universitarias. Un metaanálisis. Revista de Docencia Universitaria, 13(1), 181-202.

Penna, M. \& Sánchez, M. (2015). Evaluación de la homofobia en los futuros docentes de educación secundaria. Revista de Investigación Educativa, 33(1), 83-98.

Pichardo, J. I. (2006). Homofobia en el sistema educativo. Madrid: Cogam.

Prodócimo, E., Gonçalves, R, Rodrigues, R. \& Bognoli, P. V. (2014). Violencia escolar: Reflexiones sobre los espacios de ocurrencia. Revista Electrónica de Investigación Educativa, 16(2), 1-15. Recuperado de http://redie.uabc. $\mathrm{mx} /$ vol16no2/contenido-prodocimoetal.html

Promsex, Centro de Promoción y Defensa de los Derechos Sexuales y Reproductivos (2016). Estudio nacional sobre clima escolar en el Perú 2016. Experiencias de adolescentes y jóvenes lesbianas, gays, bisexuales y trans en el ámbito escolar. Lima: Promsex. Recuperado de http://promsex. org/images/docs/Publicaciones/IAEPeruWebGlesen.pdf

Quaresma, D. (2013). Lo legitimado y lo estigmatizado: Género y sexualidad en la educación sexual. Revista Interamericana de Psicología, 47(3), 441-448.

Red Peruana TLGB, Trans, Lesbianas, Gays y Bisexuales / Promsex, Centro de Promoción y Defensa de los Derechos Sexuales y Reproductivos (2015). Informe Anual sobre Derechos Humanos de Personas Trans, Lesbianas, Gays y Bisexuales en el Perú 2014-2015. Lima.

René, R. (2014, enero-julio). La ciudad de la homofobia. Discriminación y violencia hacia las minorías sexuales en las urbes mexicanas. Revista Latinoamericana de Geografía de Género, 5(1), 180-207.

Román, M. \& Murillo, J. (2011, agosto). América Latina: Violencia entre estudiantes y desempeño escolar. Revista Cepal, 104, 37-54.

Rondán, L. (2015) ¿Construyendo una masculinidad «alternativa» desde la escuela peruana? Una aproximación a la socialización masculina del joven en un colegio limeño de orientación alternativa. Debates en Sociología, 41, 103-131. 
Rosales, J. (2008). Las rutas del cuerpo en el currículo nacional. Un estudio sobre la socialización del cuerpo en las políticas educativas (tesis de licenciatura en Sociología). Pontificia Universidad Católica del Perú, Lima.

Valdés, A. \& Martínez, E. A. (2014). Relación entre el autoconcepto social, el clima familiar y el clima escolar con el bullying en estudiantes de secundaria. Avances en Psicología Latinoamericana, 32(3), 447-457.

Vásquez, E. (2013). Being a man in a transnational world: The masculinity and sexuality of migration (Vol. 13). New York: Routledge.

Viñuales, O. (2002). Lesbofobia. Barcelona: Edicions Bellaterra.

Weeks, J. (1998). La invención de la sexualidad. Sexualidad. Barcelona: Paidós Ibérica.

Withaker, K., Shapiro, V. \& Shields, J. (2015). Factores escolares protectores del riesgo de suicidio en adolescentes lesbianas, gays y bisexuales. Journal of Adolescent Health, 58(2016), 63-68. 
